\title{
Risk and Insurance Management in the Packaged Goods Industry
}

\author{
by Roy Damary*
}

\section{Introduction}

The objectives of this study are to determine the current needs and practices of the packaged goods industry in the field of risk and insurance management and to identify any areas of particular concern to this industry that would have an impact on insurance companies. Inevitably, for many merchandised consumer products, the main concern is with rights associated with product liability exposure, although this study is not just on product liability as such.

The study was mainly based on personal interviews with the persons responsible for risk and insurance management in major European manufacturers of packaged goods. A total of 40 interviews were conducted. Various sectors of packaged goods were covered, namely food and drinks, cosmetics and toiletries, household goods, and pharmaceuticals.

Equally important was to obtain a view from different European countries, the U.K., France, Germany, and Sweden, as well as to provide a basis for comparison with the U.S.A.

The study could not just be based on the input of packaged goods manufacturers. Personal discussions were also held with 4 packaging and/or packaging machinery manufacturers and 1 contract packer to determine the different insurance practices of the various types of companies serving the packaged goods industry.

In order to assess the legal outlook in Europe regarding product liability, interviews were conducted with a British private consumer organization (the National Community Legislative Authority) and the Department Board of Consumer Affairs in Sweden. The latter is considered to be particularly advanced in the area of consumer protection.

To obtain a comparison of European and U.S. practice in the areas of risk and insurance management practices, insurance services, and consumer protection laws, a total of 10 U.S. interviews were conducted: 6 with packaged goods manufacturers, 2 with major insurance companies, and with both the Federal Food and Drug Administration and the Consumer Product Safety Commission.

Finally, interviews with 4 European insurance companies and one broker were carried out to obtain their views on the findings of the study.

\footnotetext{
* Director, Technomic Consultants, London. Study conducted for the Geneva Association.
} 
In combining the data gathered from three sources with different points of view (the packaged goods industry, regulatory bodies and the insurance industry), the types of risk to which each sector of the packaged goods industry is exposed are identified, the risk and insurance management practices of that industry are described, and the legal outlook in Europe is discussed. Throughout the report, topics of concern are exposed, leading to conclusions relevant to the insurance industry.

\section{Risks by category of packaged goods}

In this section, the types of risk applying to packaged goods in general will be discussed. Then, to examine the types of risk as they apply to specific product groups, the packaged goods industry is categorized into four sectors: food and beverages, cosmetics and toiletries, household goods, and pharmaceuticals.

Table I in the Appendix lists the main products in each of the sectors and the types of packages used for each product.

\subsection{Types of risk}

Five types of risk have been identified as being the most relevant to the packaged goods industry and are described below.

\subsubsection{Formula errors}

Physical injury to consumers can result from lack of scientific knowledge during product formulation. This risk is particularly relevant to pharmaceuticals, but can also exist in food and beverage products and toiletries and cosmetics since these are consumer goods which are either ingested or used on the human body.

\subsubsection{Manufacturing faults}

Product contamination can result from unclean plants or raw materials, operator error, or defective filling, sealing and packaging machinery.

\subsubsection{Tampering}

The reasons for tampering are usually malice, revenge, or extortion. They can occur from internal causes, for example, employee dissatisfaction, or result from external action by an individual or even a group. This type of risk applies to products which are ingested or used on the human body (e.g. pharmaceuticals, food, drinks, cosmetics or toiletries).

\subsubsection{Faulty packaging}

Packaging plays an important role in product quality. The fault can be related to the design of the package, its manufacture, or the raw materials used. The package should be designed to suit the product it will contain and the appropriate configuration weight, thickness, surface treatment, etc. must be specified. 
In the case of glass bottles, for example, one of the more important design criteria is glass distribution. Should this be underspecified, the risk of bottle package is increased.

The decision for tamper-proof packaging and labelling requirements would also come in the design phase and could influence at a later stage the amount of risk (i.e. the number of claims) associated with the product.

In manufacturing, there is no guarantee that all the containers will be made to design specification. Although most packaging manufacturers have quality control methods to check that the design criteria are met within a specified range of limits, these checks are, for practical purposes, only random. Therefore the risk always exists that some defective containers will slip past the quality control checks.

The raw materials with which the packaging is manufactured must be compatible with the product. In foods, there is the danger that a material could give the product a certain taste or smell which would cause customer complaints.

\subsubsection{Improper storage and/or handling}

The improper storage and/or handling of raw materials as well as final products can be the cause of defective products. The most common examples of such risks include the damaging of containers during the transportation of goods, the storage of goods at too high a temperature than recommended for the product or the container, and careless storage and handling of packaging or raw materials causing contamination of the final product. In the case of much fresh produce destined for canning or other packaging (e.g. fish, vegetables, fruits), the manufacturer obtains these raw materials from small suppliers who are often inadequately insured, thus bearing their own risks.

\subsection{Types of packaged good}

\subsubsection{Food and beverages}

The most deleterious event in food and beverages, but probably the least occuring, is food poisoning. This can result from manufacturing error, defective packaging or product contamination.

Another hazard, somewhat less severe in magnitude but more frequently occurring, is related to liquids in glass bottles, where, for carbonated beverages, there is the risk of the glass bottle bursting under pressure. A similar danger lies with fermented products such as beer and wine, stored in glass bottles. Should these liquids be bottled before the fermentation process is completed, the bottle can burst or the cap blow off.

The most frequently occurring incident within this sector of the packaged goods is foreign body contamination of the product during the manufacturing process. This includes insect infestation.

\subsubsection{Cosmetics and toiletries}

The cosmetics and toiletries products are less exposed to risk than other sectors of the packaged goods industry. Only three risks were identified by the manufacturers of such products as being likely causes for claims against the company. 
The most frequent risk arises from consumer allergic reactions to personal care products. Since extensive testing is done prior to marketing a personal care product on samples of individuals to detect any irritations that might develop, such cases are usually the result of a consumer being atypical. Nevertheless, since most hygiene products are sold in large volume, a fraction of a percent of consumer irregularity can result in a significant number of claims. In these instances a manufacturer cannot legally be held liable. However, for the sake of goodwill and public image, the manufacturer usually chooses to compensate the consumer for the incident independently of his legal liability.

A second risk encountered is that of consumer misuse of the product. This is particularly relevant for hair care products such as hair colouring, and home permanent kits. Again, in such cases, if clear usage instructions and warnings against any hazards are provided for the consumer with the product, the manufacturer is not considered liable in Europe. In the U.S., it is a different story. Consumer error, carelessness or negligence does not exempt the manufacturer from liability. Again it must be stressed however that, regardless of who is at fault in these cases, in both Europe and the U.S. the manufacturer would prefer a commercial settlement with the consumer rather than be faced with harmful publicity.

The third risk mentioned by the manufacturers involves aerosol products. Incidents of aerosol containers bursting, although not common, do occur. All manufacturers are well aware of this risk and ensure pressure testing of aerosol containers as a means of eliminating this danger.

Those three types of risk were mentioned by the manufacturers interviewed as being the most relevant to the cosmetics and toiletries sector. However, there are other risks that, although somewhat infrequent, can have much more devastating effects than the cases mentioned above. Formula errors do occur in personal care products, although to a much lesser extent than in pharmaceutical products since most toiletries are well established and their contents well known. An example is the case of the baby powder called Talc Morange, a product of HOFFMANN LAROCHE, which killed some 40 babies in France in the early 1970's.

Malignant tampering in personal care products, although more frequent in foods and pharmaceuticals, represents a risk in certain European countries, whereas in others such incidents have yet to occur. An ideal example is the 1984 case in the U.K. where an animal rights group injected a bleach which can cause ulcerations in high concentration in some shampoo bottles sold by BOOTS. This incident led to a check of all stock of the product as well as to a product recall.

\subsubsection{Household goods}

The most common cause of claims in household goods is damage to clothing or furniture: bleaches damaging clothes or cleaners and polishes stripping the finish off of kitchen equipment and units or furniture. These are normally claims of reasonably low amounts. Damage to clothes can be the result of leaking bottles which are either defective or have been damaged in storage and handling. Misuse of the product in clothes washing can also be involved. Stripping of surface finishes can arise from faulty manufacture such as operator error (such as forgetting to clean the reactor after a batch of one product causing contamination to the following batch of another product), operator sabotage, and off-spec raw materials. 
Household pesticides and concentrated chemical cleaners are also a relatively important risk area. Accidents generally result from consumer misuse of the product, e.g. not reading the directions properly and not using the correct dosage. The risk and insurance manager of a company that manufactures both pharmaceuticals and insecticides reported that the insecticides were the cause of many more claims than the pharmaceutical products. The difference in the amount of claims for the two products resulted in them taking out a separate product liability policy for their insecticides, lest their claims record for general product liability deteriorate.

In considering the fact that many household products are potent chemicals, it appears that, based on the types or packaging used for these products, the risks are not as clearly recognised by the manufacturers as they should be. For example, as the organiser of the U.K. National Consumer Protection Council pointed out, products such as weed killers and bleaches do not have child-proof packaging and this has been the cause for consumer complaints. Soda crystals used for cleaning, for instance, can easily be mistaken by a child for sugar and yet they are packaged in a simple carton. In France, it is common to package concentrated chemicals in flexible, individual use portions. This type of packaging is not used in other European countries nor in the U.S. because it is not thought to be strong enough to contain hazardous chemicals.

\subsubsection{Pharmaceuticals}

The pharmaceuticals sector is exceptional in that it experiences very few claims, but the few are usually catastrophic and receive international publicity. The pharmaceutical companies are faced with two business risks; the first which is not relevant to this study, is related to R\&D investment. Huge sums are invested in the research and development of new drugs, with no level of certainty as to the return on that investment. And if a company is lucky enough to develop the one drug in ten which is successful, once it is marketed the company faces the second risk which is very relevant to this study; that of formula risk.

There is the continual danger that over a long period of time a drug will cause side effects. These side effects can appear after a few days, a few months or several years. There are a few cases which illustrate this problem. One of the most prominent ones is Thalidomide-Contegan, a sedative or calming drug which was given to pregnant women in Germany, Sweden and the U.K. in the mid-1960's, and resulting in the birth of babies without limbs. Clinical testing on animals cannot determine human reaction to a drug, and, as a result, pharmaceutical companies take an enormous risk in commercialising every new product.

To further complicate matters, the liability laws are stricter for pharmaceutical products than for other packaged goods. In Germany, for example, strict liability applies only to the pharmaceutical industry. One U.K. manufacturer claimed that there was also a movement in that direction in the U.K. where a voluntary acceptance of strict liability is now being recommended in the context of clinical testing to the members of the Association of the British Pharmaceutical Industry, and as a result some manufacturers have approached insurers to obtain an appropriate cover in compliance with this recommandation.

One of the most controversial issues in the EEC directive on liability at the moment is the question of development risk, which is particularly relevant to formula risk and hence to the pharmaceutical industry. The questions being asked are: 
i) Should the manufacturer still be held liable when a consumer suffers injury from his product if that manufacturer was unaware of any defect associated with his product? The product would then be said to have a latent defect, (associated with the expression "development risk")*.

ii) If the product has been on the market for some time when a consumer sustains damage from it, does one judge the defect based on the technology and testing procedures known at the time of the product's manufacture or at the time the claim is made? This type of defect is distinguishable from that in the first question and would be called a subsequent defect, (associated with the expression "state of the art")*.

These issues will be further discussed in a later part of this report.

Other than the formula risks, there are two other problems which plague the pharmaceutical industry, both requiring certain packaging requirements. The first is tampering, illustrated by the Tylenol case in the U.S. which resulted in several poisoning incidents in 1982 . The other is related to the hazards of drugs in the presence of children. For protection from these risks the manufacturers must invest in the development of tamper-proof and child-proof packages.

Another packaging problem that arises occasionally is related to aseptic of pharmaceutical products, viz, the failure of the package to function properly in maintaining sterilisation. This, however, concerns the packaging manufacturers more than the pharmaceutical companies themselves and it applies to medical fluids stored in sterile containers and used by hospitals rather than to pharmaceutical products sold directly to the consumer.

The possibility of misuse of drugs is a much more relevant risk to the manufacturer in the U.S. than in Europe. In the U.S., if a physician wrongly prescribes a drug, or should a consumer knowingly misuse a drug as in the case of suicide or addiction, there is a possibility that the manufacturer be held liable and have to pay compensation. In Europe this would be highly unlikely. The pharmaceutical industry in Europe and the U.S. is strictly controlled to minimise the risks of misuse. Potent drugs require prescriptions, must be purchased through a pharmacy and are well labelled. In Sweden, all drugs, prescription and over-the-counter, must be sold through state-owned pharmacies. This greatly minimises the risk of drug misuse, and particularly tampering, in Sweden.

\section{Risk and insurance management}

The main responsibilities of the risk and insurance management of a company are:

1) To identify and minimise the risks to which the company is exposed.

2) To determine the types and amounts of risk which should be carried internally by the company, usually including the so-called burning costs, and those risks which should be covered by insurance companies.

3) To choose the appropriate insurance policies which will adequately cover the risks which the company itself either cannot financially bear or has chosen not to bear.

* John G. Cowell, deputy Secretary General of the European Insurance Committee, Product Liability: The End of the Community Trail?, Paris, March 1983. 
The risk and insurance management practices in the packaged goods industry vary from company to company depending on the sophistication of the company in this area, on the laws and customs of the country in which the company operates, and finally on the attitudes of the risk manager and senior management. Two issues, both linked to two distinct philosophies, were identified during this study. The first deals with the amount of risk carried internally by the company, i.e. the burning costs incurred, and the second is related to the breadth of the cover, i.e. the cause versus effect basis of policies.

Concerning the first issue, the majority of companies interviewed incurred a certain amount of burning costs for the following reasons:

- to have the manoeuvrability of making commercial settlements which is critical to maintaining customer satisfaction;

- to avoid trading money with their insurers;

- to reduce premiums.

In determining the types and amounts of risks to be borne internally rather than externally, distinctions are made between:

- risks that are frequent in occurrence and small in magnitude versus catastrophe risks which are infrequent but financially unacceptable;

- business or company risks which are within the control of the company versus risks due to external factors which the company cannot control.

Only a minority of the companies were found to operate under the philosophy of covering most of the risks externally and incurring minimal or no burning costs. The arguments for this minority position were:

- insurers act as a neutral buffer between manufacturers and claimants and this actually reduces the number of claims settled;

- insurance companies are better equipped for claims handling and it is therefore more economical to delegate to them the insurance administrative work;

- insufficient discount on premiums compared with the burning costs;

- the unpredictability and long settlement periods of liability claims make it a nuisance to deal with them;

- a small deductible is applicable only to companies with large number of small customers, which means the occurrence of a greater number of smaller claims.

The second issue (concerning breadth) resulted in a split of opinions among risk managers. Some favoured the development of broadly stated covers based on effect rather than cause of an incident. They felt that the concept of an "all-risk" policy insuring against product failures or defects in general rather than having the existing distinctions between product liability, integrity, guarantee and recall would offer better protection to the manufacturer. Others believed that the policies currently on the market, based on cause rather than effect, help them identify the particular risks to which they are exposed, and minimise premiums. To them, an extensive cover translates into higher premiums, does not encourage discipline in preventing product failure, and, in some instances, will cause a company to assume the cost of more claims. 


\subsection{Risk identification}

Those packaged goods companies that are more progressive in the area of risk and insurance management attempt to identify risks before the occurrence of incidents rather than after the fact. The risk manager interacts with the various people in the company who are involved with different aspects of risk, including the safety and security managers, as well as the design, production and quality control engineers.

Many companies are incorporating safety and security in the risk and insurance management department, although some still have these functions under the personnel department. It is being realised that, in order to improve the function of risk management, all persons involved with risk should, on issues of risk, have to liaise with a single individual. This would concern the production director, the need of $R \& D$, quality control manager, the personnel director (traditionally responsible for safety and security), and the financial director. If feasible, the risk manager makes a point of regularly visiting the company's manufacturing facilities as a risk identification exercise.

Many companies also set up customer service departments to obtain first hand information on consumer dissatisfaction with their products. This in many cases helps identify possible risks before a major claim occurs. Furthermore, the analysis of claims loss history can determine frequently occurring causes of claims and thus bring to light existing risks.

\subsection{Risk reduction}

All companies, regardless of the risk and insurance management philosophy applied, practice some form of risk reduction methods either to minimise their insurance needs, to lower their insurance premiums by having a good claims loss record, or simply out of a sense of responsible management. Risk reduction methods can be classified into those which reduce the chances of an event occurring and those which lessen the impact of the event once it has occurred.

Methods of reducing the chances of an event occurring begin in the design and development phase of the product and its packaging and exist throughout the manufacturing process.

\subsubsection{Product development}

Prior to its market launch, a product is thoroughly tested for adverse reactions. In the case of cosmetics and toiletries, for example, testing for allergic reactions or skin irritations is a must, while pharmaceutical products undergo a much lengthier and extensive testing procedure since their long term side effects on several future generations must be investigated by experimentation on animals. Legislative authorities and consumer organizations seek to reduce the risk to the consumer by setting standards and specifications which the products must pass.

\subsubsection{Packaging}

In setting the package design specifications, the packaged goods manufacturer can reduce many of the risks to which he believes himself to be vulnerable, such as tampering, childrelated accidents or consumer misuse of the product. 
Tamper-proof and child-resistant packaging as well as package labelling are also the concern of public consumer organizations. Many packaged goods products have labelling requirements which go as far as informing the consumer of the contents of the product, the hazards which may be associated with its use, and directions as to its proper use.

In the U.S., the Federal Hazardous Substance Act, sets labelling standards for hazardous household products which are enforced by the U.S. Consumer Products Safety Commission. Moreover, all new drugs have had to have approved labelling by the Food and Drug Administration (FDA) since 1938. The FDA has also established certain levels of tamper-proof packaging requirements for drugs. The Poisoning Prevention Packaging Act passed in 1970 sets standards on the packaging of certain products and enforces child-resistant packaging for many household products. Packaging is determined as being child-resistant if, out of a sample of children between the ages of 3 and $5,80 \%$ are unable to open the container.

Tamper-proof and child-resistant packaging requirements are not yet imposed by governments in European countries. Thus, today in Europe, the decision of whether such requirements are necessary as part of risk prevention lies principally with the product manufacturer. There are plans, however, to impose child-resistant packaging requirements in the United Kingdom. In the Netherlands, the Board for Consumer Policies is in agreement with trade and industry as to the need for child-resistant closures and will be drafting guidelines in the near future based on the government's recent decision to impose such requirements.

\subsubsection{Quality control}

To reduce manufacturing risks, virtually all packaged goods manufacturers introduce quality control measures in their production process. Sample of the raw materials, semi-finished and finished products are analysed regularly to ensure that manufacturing specifications are maintained. Containers are pressure tested before and after the filling operations to check for breakage, leakage and other defects. Although these are, for practical purpose spotchecks, containers which are more risky, such as aerosols, are normally individually checked.

\subsubsection{Product coding}

Product coding and identification is an important means of risk control. The codes which most packaged goods manufacturers adopt include not only the date, and the manufacturing facility identification, but the batch number or production run as well. In terms of minimising the product liability risk, risk managers identify the following reasons for adopting a product coding system:

- To allow a manufacturer to distinguish his own products from similar products on the market.

- To trace a product problem to the manufacturing stage and refer to quality control records. This may be particularly important in establishing whether a manufacturing fault exists and in the development of a defence against a claim.

- To identify products manufactured during a period when a confirmed quality fault existed. This might arise if, following the investigation of a complaint, it is necessary to contact other customers supplied during the same period. 


\subsubsection{Production records}

Adequate production and quality control records for use in the investigations of customer complaints are kept by a vast majority of manufacturers to facilitate the correction of problems and hence to avoid risks. In the European countries examined for this study, particularly in those countries where strict liability is enforced for the pharmaceutical industry (Sweden and Germany), the manufacturers of pharmaceuticals are required to maintain records to show the manufacturing history of each drug. In the U.S. this is called operating under "good manufacturing practice". Quality control samples tested in the laboratory are retained for a certain period of time to clarify any future allegations of product failures.

\subsection{Loss control}

In addition to methods of reducing the chances of an event occurring, there are methods of reducing the financial impact after an incident has occurred. Three such methods, product recall, contingency planning and claims control, will be discussed as they relate to the packaged goods industry. Table $\mathrm{V}$ in the Appendix shows the percentage among the companies interviewed in Europe and the U.S.A. that had a formal product recall plan and which practised contingency planning.

\subsubsection{Product recall}

The introduction of a plan of action for the recall of a product in case of a defect is designed to speed up the process of recall as well as minimise the costs associated with it. Separate product recall plans are normally devised for each product type within a company since often the difference in distribution channels and consumers might require different procedures.

Product recall efforts and costs tend to be the least for pharmaceutical companies who are required to maintain detailed distribution records of their drugs. For them, the steps required in tracking down and recovering the individual product items are minimised. Food and toiletries manufacturers, on the other hand, must rely on costly methods such as advertising to recall their products from the market.

\subsubsection{Contingency planning}

Contingency planning attempts to identify alternative suppliers and methods of production in order to eliminate the risk of a business interruption due to either a loss of a main supplier, an equipment failure or a plant shutdown.

The traditional risk reduction method of double sourcing can be applied to the packaged goods industry for the raw materials from which the product is manufactured. However, it is not quite applicable for packaging materials. In the packaged goods industry, there is a strong dependency by the packaged goods manufacturers on their packaging materials and systems suppliers. Hence, risk reduction is achieved, not by having alternative suppliers, but by choosing a single supplier with a reputation of absolute reliability. A stable long-term relationship with a packaging supplier is thus a must for packaged goods manufacturers in their aim of reducing risks of business interruption. In this context, the question of sourcing becomes a method of reducing the probability of the occurrence of an event (i.e. business interruption), rather than a method of reducing the impact of an event after it has occurred. 
In identifying alternative production routes, the various manufacturing departments of a packaged goods company can include the use of contract manufacturers, a variation in processing steps, or the increase in production of another plant manufacturing the same product. Such contingency planning is particularly relevant to packaged goods, since these products, which are mainly branded names, are particularly vulnerable to an absence, even short-term, from the market.

\subsubsection{Claims handling}

A risk manager of a U.S. packaged goods manufacturer mentioned that one way of practicing risk reduction is after-the-fact claims control. Improving claims handling can reduce the amount of total indemnity on product liability for a company. Furthermore, close control of claims handling and records keeping by risk managers can better identify the risks to which the company is exposed and thus enable the appropriate risk reduction methods to be applied.

\subsection{Outside services}

\subsubsection{Captive insurance companies}

As can be seen in Table IV in the Appendix, a significant number of manufacturers interviewed had a captive insurance company. In addition to the obvious financial benefits of reclaiming a portion of the premiums by having the insurer reinsure with the captive and of tax exemptions on the profits of the captive located in certain geographical areas, there are other incentives to have a captive insurance company:

1) If the company feels that it is less risky than most other companies and consequently does not want to pay the average premium rates.

2) If a company cannot get a certain cover. For example, if it is not able to get cover for its U.S. operations from European insurers due to the greater risks involved with that market.

3) When premium discounts for deductibles are not sufficiently attractive. Having a captive insurance company enables the company to tailor its cover to meet its own requirements.

4) If the company is located in a country which has restrictions on the amount of money that can be taken out of the country. By having the insurer reinsure with the captive, the company can thus have the premiums paid to its captive outside the country.

It is not particularly attractive for a captive insurance company to give insurance for liability cover as this does not represent significant premiums. Normally, it is more interesting for a captive to deal with the policies involving the greatest cost to its parent company, such as fire, consequential loss and difference in condition covers. Furthermore, it is difficult to assess the profits of a captive giving liability cover owing to the fact that liability claims have long settlement periods and that the settlement amounts of the claims are not easily predictable. The incentives are greater in the U.S. than in Europe to have a captive insurance company, since manufacturers are required to have workmen's compensation insurance. This is a major expense for them, as such a scheme is not provided for by the state. In most countries in Europe, however, employee accident insurance is provided for by the state, thereby eliminating a major incentive for the companies to have a captive. 
In Germany, the insurance market is strictly controlled by the Federal Supervisory Office for Insurance. A captive insurance company cannot exist per se since it must be officially registered and licensed as an insurance company. All conditions of insurance must be approved by the FSOL before a policy can be issued. This strict supervision prohibits many companies from having captive or subsidiary insurance companies. Only the giant companies such as HOECHST, BAYER and LUFTHANSA can derive an economic benefit from having a captive. A risk manager of a German manufacturer estimated that it is not of interest for a company to form a captive in Germany unless it has at least DM 10 million in total cover, all insurance combined, and of DM 5 million for property insurance.

\subsubsection{Brokers}

Brokers are extensively used in the U.K. and France, to a lesser extent in Germany and minimally in Sweden.

In France, it is common practice for companies to have captive brokers, the advantage being to take a share of the brokerage commission paid by the insurers. Companies that have captive brokers, however, do not necessarily benefit in the long run since internal brokers may be less informed about the insurance market than external brokers.

In Germany brokers are used but do not play as powerful a role in the insurance market as they do in the U.K. and France. A captive broker can be no more than the insurance manager and generally serves only as a means of obtaining the brokerage discount. There exist only two strong brokers in Germany, and there are 156 registered captive brokers.

In Sweden, brokers are not even allowed. However, a number of them do operate under the title of consultants. One item on the agenda of the Swedish governmental committee responsible for instituting the laws regulating the insurance market is to legalise the existence of brokers in Sweden. Although there does not appear to be a strong need among manufacturers for brokers, the philosophy of the Swedish industry is to have a free system whereby anyone who desires to start a business should be allowed to do so, and to let the laws of supply and demand determine survival of businesses.

\section{Categories of insurance}

Six areas of insurance particularly relevance to or for which there are particularities associated with packaged goods are identified as follows:

- Product liability;

- Consequential loss;

- Product Recall;

- Extortion;

- Product Integrity;

- Product Guarantee. 
A percentage breakdown of these types of insurance covers as they are used by the manufacturers interviewed is given in the Appendix in Table III. Table VI gives the range of limits and deductibles obtained in this study for the various policies. The practices in each of these areas as well as other issues concerning the insurance industry are discussed below.

\subsection{Product liability}

All companies interviewed had some form of product liability insurance. The majority had a combination of planned self-insurance with the catastrophe risk transferred to commercial insurers. This option allows them the manoeuvrability they require for making commercial settlements. In most cases, the product liability cover is part of a general liability policy, with the subsidiaries having a primary layer of cover obtained either locally or by arrangement of the parent company. Many of the risk managers reported that having local covers for subsidiaries has the advantage of facilitating claims handling.

The amount of cover is normally chosen based on the country's norm or standard for commercial business rather than on the turnover of the company. In some countries, the state regulates the amount of insurance a company is allowed to have. A global excess or master cover, frequently made up of several layers, tops the primary cover. The limit of the excess cover is chosen based on availability, cost, practices of similar companies, broker's opinion and the insured's risk-aversion. The excess cover serves the various functions:

1. It covers the difference in conditions of the local policies by having a broader wording.

2. It covers the difference in limits of the local policies by having a broader limit.

3. It contains a step-down clause which would cover liability should the primary layer be exhausted. In other words, if the accumulated claims resulting from an incident exhaust the primary layer of product liability insurance, the excess cover will pick up any further claims regardless of whether or not they are below the limit of the primary layer.

In certain instances, when some of the subsidiaries of the companies have inadequate primary covers, the companies opt for a buffer policy between the primary and excess covers.

A few multinational companies were found still to maintain local primary and excess covers for each of their subsidiary companies individually. These companies, however, were few and far between, and most were in the process of assessing the financial implications of switching to global excess covers. Risk managers were well aware of the financial benefit of volume-buying and of the improved claims handling in multiple exposure cases associated with using global excess covers. An example of multiple exposure would be a company which develops a product in one country, manufactures it in another, and sells it in still a third. In such a case, a company stands the risk of being held liable three times if one of the products sold is found to be defective and causes damage. Dealing with one insurer in this situation, rather than three, can not only facilitate matters for the manufacturer but can possibly reduce the amount of total indemnity as a result of better claims coordination.

Deductibles on primary product liability covers can be an indication of a company's burning costs, but quite often reflect other factors, such as insurers' attitudes or market conditions. Pharmaceutical companies, for example, are obliged by their insurers to take extremely large deductibles, equalling as much as their total primary layer of cover, because the risks involved are unknown and unpredictable. Also, if the insurance market is soft, meaning that premiums 
are kept low due to intense competition among insurers, then the manufacturers are not compelled to take a deductible in order to lower their premiums. The discount on deductibles is then no longer sufficiently attractive.

In Germany and in Sweden there exist for the pharmaceutical industry liability insurance schemes to which all suppliers of pharmaceuticals in the respective countries contribute jointly to a "pharmapool". This then takes care of any claims resulting from side effects of a drug sold in that country. Both pharmapools specify limits to liability. In Germany the pharmapool is legally enforced, whereas in Sweden it is self-imposed. Having pharmapool coverage, however, does not exempt Swedish and German pharmaceutical manufacturers from requiring a product liability policy, since it is necessary for them to have coverage for side effect claims which occur outside their countries and for their other areas of operation.

General liability covers in Germany and in Sweden can be separated into property damage and bodily injury. A company can choose to have different limits and deductibles for each category of liability, depending on the risks to which it is exposed. For example, a company that manufactures both pharmaceuticals and industrial chemicals might have a greater limit for bodily injury than for property damage since the risks associated with pharmaceuticals are greater in magnitude (i.e. represent a greater catastrophe) than risks of industrial chemicals. On the other hand, property damage claims due to the industrial chemical products are the most frequently occurring types of claim (as opposed to the higher pharmaceutical bodily injury claims). The company, therefore, would have a greater deductible on the property damage cover. In this way the policies are more tailor made to suit the needs of individual companies, and there is less likelihood that a company would be either over-insured or underinsured in a particular area.

Financial loss liability coverage can be obtained as an extension to the product liability policy. This would be coverage of a financial loss incurred without bodily injury or property damage. An example would be a product found harmful being withdrawn and thereby causing a loss of profit to the retailer. Another example would be bottles of whisky which, owing to defective screw tops, cannot be opened and result in a product loss to the whisky producer despite the fact that the whisky was not damaged in any way. The deductible on a financial loss liability cover is normally a percentage, typically $10 \%$, of the financial losses incurred. Three U.K. companies, one French company and one German company in the total 22 manufacturing companies interviewed were found to have financial loss liability cover.

Some European insurers, particularly the German ones, refuse to include the U.S. market in global excess covers. Those who have a U.S. subsidiary offer a separate U.S. primary and excess cover handled locally. The reason the U.S. is often excluded by European insurers from global covers lies in its particular situation resulting from the social structure (the lack of a social scheme for employee accident insurance) and the legal structure and practice (heavily stressed consumer protectionism favouring high compensations). Insurers feel that having a local U.S. cover handled by a U.S. subsidiary has the crucial advantage of enabling the insurer to react immediately. Moreover, this allows the insurer to be better informed on the special U.S. market situation which, in the last 15 years, has created tailor-made coverages. Examples of U.S. specific policies would be personal injury and liquor liability, which is a clause in a U.S. employer's liability policy that covers third party claims resulting from an accident caused by the intoxication of an employee at an office party. 


\subsection{Consequential loss}

Consequential loss coverage, otherwise known as business interruption insurance, is also considered a fairly standard policy for packaged goods manufacturers to have, although as can be seen in Table II, it is not as common as product liability. This policy covers the gross margin, which is the fixed costs added to the profit margin, during a business interruption due to a fire or other natural disaster. The emphasis of this policy in Europe and in the U.S. is slightly different, and it is worthwhile giving a brief summary of the difference.

In Europe, the consequential loss policy is based on loss of profits, meaning that the gross margin is covered for a predetermined time limit. In the U.S., however, the cover is based on gross earnings, meaning that the gross margin is covered until the company manages to get back in full operation, (not necessarily the same as full sales level). There are advantages and disadvantages to both schemes. Should the time it takes the company to get back in full operation be less than the specified time limit of the policy (normally six months or a year), the European policy would cover financial loss due to a decline in sales until the original sales level is regained or the time limit is reached, whichever comes first. On the other hand, if the time limit it takes the company to get back into operation is greater than the time specified, the European version of the consequential loss policy would not cover the full period of business interruption for the company. The U.S. policy would not provide cover until the former sales level was regained in the first case and would provide full business interruption coverage for the company in the second case.

Conventional consequential loss insurance does not have much relevance to packaged goods for two main reasons. First, the cover deals with the loss of sales due to a business interruption arising from a fire, a natural disaster, or machinery breakdown. It fails to include some critical causes of a packaged goods manufacturer's inability to deliver the product, e.g. tampering or extortion. Second, although the cover does take into account the loss of sales caused by a brand name's absence from the market due to a business interruption, it does so on a very limited basis. In examining the difference between the European version of the policy versus that of the U.S.A., it is clear that in Europe consequential loss insurance offers a greater opportunity of recovering lost profit from market absence (since it focuses on sales rather than the ability to produce). Nevertheless, the cover is still inadequate for the purposes of packaged goods companies. It deals with regaining former or expected sales level rather than market share, which is the more relevant measure of loss since the size of the market could be either increasing or decreasing. Furthermore, it normally limits the indemnity period to six months or a year, which is insufficient to re-establish market presence of a consumer product. This limit is based on investigations as to the length of time required to replace various parts of a manufacturer's facilities. In Germany time limits exist for the reimboursement of wages as well as for machinery replacement during a business interruption, standard practice being 6 months for the former and 12 months for the latter (with a maximum of 24 months for either).

Thus, packaged goods manufacturers often opt not to take consequential loss insurance. Those that do are more than likely diversified into non-consumer product areas. And even they are selective as to which of their facilities to insure against consequential loss. For example, one of our respondents, a manufacturer of household goods and industrial chemicals, did not cover the plants which manufactured its household goods, the reason being that the gross margin loss for the first year that any such product is off the market would be marginal compared to the profit loss in the consecutive years due to the drop in consumer awareness 
of the product, and hence in market share. Some packaged goods companies might require consequential loss insurance to cover certain factories which are unique in manufacturing a particular product, i.e. one to which contingency planning methods cannot be easily applied.

Consequential loss covers are normally local covers for individual subsidiaries on top of which sits an all-risk "Difference in Conditions" cover for accidental damage and material loss in addition to consequential loss. In Germany, all-risk property damage and consequential loss policies do not exist. Instead, the policies are formed based on cause, resulting in separate policies for fire, theft, machinery breakdowns, etc. Hence, business interruption insurance is of two types:

i) due to fire;

ii) due to machinery breakdown.

This has advantages as well as disadvantages. A pharmaceutical company whose conditions of hygiene are strictly controlled by authorities is much less exposed to a consequential loss due to a fire than to machinery breakdown. It can therefore tailor its risk coverage better by having separate policy for different types of risk than by having an all-risk cover. The disadvantage with not having an all-risk cover is that some risks might not be covered by any of the individual policies.

\subsection{Product recall}

In Europe, recall of packaged goods is a relatively rare occurrence when compared to the U.S. This type of cover is somewhat used in the U.K. and France as an extension of the product liability policy; it is used even less in Sweden and Germany.

In Europe, product recall covers are normally either an extension of product liability or are considered as separate policies. In the U.S., however, a major change has occurred whereby product recall is linked to product integrity (to be discussed in the next section) rather than liability. In the past, product recall policies had a limited acceptance in the U.S. industry because they offered limited coverage and their costs were too high and the deductibles were also too high. The policy did not even cover the cost of the product which was to be destroyed once it was recalled. Now, however, product recall cover would take care of all expenses incurred to remove the product from the market, to inspect it in order to identify or confirm the defect, and to destroy it. The amount of the recall cover is usually related to turnover as well as area of distribution.

In Sweden, if the authorities of another country ask a Swedish manufacturer to recall a product from that country, the Swedish insurer of that company can request that the company withdraw its products from all markets in order to avoid claims. Nevertheless, recall covers are issued in Sweden on a very restricted basis. Product recall cover in Sweden is mainly used by the car industry and for household products such as electrical appliances. The policy was introduced in Sweden about two years ago. Currently one insurer estimates there are less than ten policies in total. These product recall policies usually involve high retentions by the companies. In some product liability covers in Sweden, recall is covered only if a claim occurs. In others, however, there is no such restriction. It is only necessary that there be a suspicion of a product defect which might be harmful for the policy to take effect. 
Product recall coverage in Germany is of marginal interest to this study since it only applies as third party recall to suppliers of the automobile industry. It is designed to protect companies from recall costs resulting from defects of their suppliers' products. A car manufacturer, however, would not be able to obtain a recall cover for his own recall costs because most German insurers would consider this a business risk. They believe these to be the responsibility of the manufacturer himself. German insurers are also of the opinion that, offering a product recall cover would encourage manufacturers to undertake frequent recalls for insignificant reasons (e.g. wrong colour), would cause carelessness, and would give manufacturers the opportunity to manipulate insurers, for example by including in a recall unsellable goods which have been in storage.

The German insurance authority, called the Federal Supervisory Office for Insurance, prevents foreign insurers with a different philosophy than the German insurers from entering and capturing the German recall market: they simply do not allow the cover for the German market. Although there have been discussions by the German insurance companies, industry and politicians to include recall covers on a wider basis, at the moment there exist no models on the market to insure product recall costs for non-automobile related companies.

There are several reasons why a company might not feel that it needs product recall cover. Pharmaceutical companies, for example, have such stringent record keeping requirements enforced upon them that they can easily trace their products, even over-the-counter drugs, without a great deal of cost. In Sweden, drugs can be sold only in a state-owned distribution system, which simplifies even more a recall action. Good coding practices, detailed record keeping of product shipments, and a thorough product recall plan can minimise product recall costs and thus make insurance look less necessary.

Some companies argue that the cost of recall alone is marginal when compared to the loss of image, and therefore of future sales, consequent to the recall. This reasoning is the basis for the linking of product recall to product integrity coverage in the U.S.A.. In this way, both direct and indirect costs of a recall are covered

A company which is diversified, having a mixture of branded products in different and unrelated industries, is less vulnerable in the event of a recall since a recall of one of its products would not be likely to affect the financial performance of its other products.

\subsection{Extortion}

Extortion cover is very rarely used in the European packaged goods industry. Such policies cover the direct costs such as detectives and extortion demands (unless advised not to be paid by the police), but do not cover the consequential effects of the extortion act. They are normally linked to kidnapping and ransom policies or, in the case of the U.S.A., are incorporated into product integrity coverage.

In France it is illegal to insure against extortion. In Sweden, extortion is usually made part of the political risk, an area which has recently been explored by the Swedish insurers. It is only used by international companies for their foreign markets. In Germany, although it is not illegal to insure against extortion, the Federal Supervisory Office for Insurance does not provide insurers with a licence to offer such a cover, nor for kidnapping and ransom.

The U.S. companies interviewed were particularly sensitive about revealing whether or not they have extortion cover. This is an indication of the greater exposure to extortion risks in the U.S. than in Europe. 


\subsection{Product integrity}

Product integrity cover is a U.S. concept. This type of policy was developed by U.S. insurers in November 1982, immediately following the Tylenol incident which occurred in October 1982. This case, which involved the poisoning deaths of individuals due to a tampering incident involving the pain reliever Tylenol, was estimated to have cost its manufacturer, JOHNSON \& JOHNSON, about $\$ 100$ million, although it is not clear whether this is direct cost only or total financial cost. It was estimated that $\$ 60$ million was spent on product recall alone.

The Tylenol case raised some new issues among insurers and insureds. Prior to this incident, a limited form of integrity cover was available for the food industry, but it did not apply and was not offered to the pharmaceutical industry. As a result, JOHNSON \& JOHNSON were only covered for product liability and not for the costs of the recall, testing and disposal of the product, the damaged goods, the loss of profits resulting from the event, or the cost of development for the tamper proof packaging to be used on their new products. Nevertheless, they have sought compensation from their property damage, business interruption, and product liability excess covers on the basis of various arguments.

JOHNSON \& JOHNSON have claimed that they should be compensated from their property damage cover since the tampering incident has damaged their product, which is their property. It can easily be argued, however, that the product was no longer the property of JOHNSON \& JOHNSON since it had already been sold and it is fairly obvious that in purchasing their property damage policy, JOHNSON \& JOHNSON had not intended such an incident to be covered.

They have also been trying to obtain compensation on their business interruption policy by advocating that the tampering can be interpreted as an external cause and therefore applies to the consequential loss cover. This argument is invalid, however, since business interruption coverage is generally applicable to fires and specifically excludes product impairement as a cause.

Another issue involving the Tylenol case is whether it is to be classified as tampering or extortion. Initially it was perceived as a tampering incident. An extortion note, however, later appeared, but there were doubts as to its legitimacy. In any case, the incident cannot be defined as extortion since the note was received after the deaths occurred, and hence even if JOHNSON \& JOHNSON had had an extortion policy, the Tylenol incident would not have been covered.

JOHNSON \& JOHNSON also believe that their excess cover should bear some of the recall costs since, by removing the product from the market, they reduced the risk of other claims occurring. The underwriters, on the other hand, are arguing that the excess liability coverage excludes recall. They had written the umbrella cover to supplement JOHNSON \& JOHNSON's primary policy, written by JOHNSON \& JOHNSON's Bermuda-based captive insurance company, which excludes recall coverage. To complicate matters, the wording of the excess cover is slightly different than that of the primary cover, allowing room for interpretation. And to add further to the confusion, it is alleged by the insurers that the broker who negotiated the cover for JOHNSON \& JOHNSON knew of the differences in the wording of the covers and yet conveyed that knowledge to neither the excess insurers nor JOHNSON \& JOHNSON. 
In April of 1983, six months after the occurrence of the Tylenol incident, it was estimated by one of the largest U.S. brokers that between ten and fifteen insurers offered product integrity coverage. The capacity of the integrity cover at that time was $\$ 150$ million. Since then, however, the market has contracted and is still shrinking. Today, there is a maximum of five insu rers who provide the cover and the capacity has dropped to around $\$ 25$ million (although a limit of $\$ 100$ million can be obtained with facultative reinsurance). Despite the fact that insurers have reduced their supply, the demand for the cover appears to have remained the same if not increased. According to an estimate by CHUBB \& SON INC., one of the first insurance companies to provide the cover and who currently holds approximately $40 \%$ of the market for product integrity in the U.S., the total market for insurers in the U.S. in the area of product integrity and recall protection is about $\$ 15$ million in premiums.

The integrity policy is targeted for consumable products which includes foods, pharmaceuticals and cosmetics. It is not intended for such products as electrical appliances. The CHUBB policy is intended to cover the following:

- expenses of recalling a product, either voluntarily or under government mandate, incurred by both the distributor and the manufacturer;

- the cost of inspecting, testing and destroying recalled product;

- the selling price of all goods not sold as a result of the recall;

- expenses to rehabilitate, reestablish, and replace the product;

- extra expenses to launch a new product as a mean of mitigating the loss, which includes $\mathrm{R} \& \mathrm{D}$, promotion and advertising.

The integrity policies typically exclude:

- known conditions;

- acts, errors or omissions of the insured's officers;

- bodily injury or property damage;

- normal market fluctuations that lead to business losses;

- latent defect or deterioration (a defect which becomes apparent several years after the product's manufacture);

- losses traceable to the use of ingredients banned by government agencies;

- extortion payments;

- war and nuclear risks, unless a product is deliberately contamined with a radioactive substance.

Risk selection criteria in looking at a prospective client for the insurers are as follows:

- the financial condition of the company;

- the stability of the industry the company is in;

- product line diversification;

- the degree to which any one product contributes to a company's net income;

- the company's quality assurance and loss control programmes; 
- packaging procedures (particularly important for food and drug companies);

- the geographical spread of the products;

- the shelf life of the products;

- the distribution chain for the products;

- the company's history of tampering or contamination problems;

- the company's employee relations programme;

- the company's crisis management programmes.

The factors listed above are used by the insurers in determining the premiums of the cover, which, according to CHUBB \& SON INC. can be anywhere from $\$ 500,000$ and up for a Fortune 500 company, or between $\$ 20,000-\$ 30,000$ for a smaller company with less risk exposure. Deductibles on the cover depend mainly on the size of the company. CHUBB \& SON INC. state that for a Fortune 500 company, the deductible might range from $\$ 500,000$ to $\$ 2$ million, while for a smaller company of $\$ 15$ million to $\$ 20$ million in revenues, the deductible would be less.

Only one of the packaged goods manufacturers visited in the U.S. was found to have product integrity insurance. The limit of the cover was for $\$ 100$ million (the alleged loss of JOHNSON \& JOHNSON due to the Tylenol case) and it had a deductible of $\$ 10$ million. This cover had been obtained in 1983 when the capacity of the market was at its peak. Several of the other U.S. manufacturers claimed that they had considered or were in the process of considering the policy. Reservations that these companies had about the cover were:

- the breadth of the terms;

- the difficulty in relating the loss of sales to a particular incident while excluding all other factors also affecting sales.

These factors evoked fears in the manufacturers that controversies would likely arise between insurer and insured over individual interpretations of the policy and over profit loss determinations.

In determining profit loss under an integrity policy, the profitability of the company prior to the product incident is compared with its probable future profitability. To accomplish this, the company must provide its insurer with extensive market data collected over the past and with a forecast of its expected future profits. Manufacturers of consumable products are usually very market oriented and would normally have sufficient market data gathering mechanisms and often use sophisticated market research techniques, thereby providing the insurer with the required information. To solve the problem of possible disagreements between themselves and their clients, CHUBB \& SON INC. have provided their product integrity contract with an arbitration clause specifying the selection of a disinterested third party to settle any differences over the amount of loss.

\subsection{Product guarantee}

Product guarantee insurance is the replacement of the cost of damaged or defective products, which is usually excluded in product liability policies. It was determined that such a cover is not used by the packaged goods industry either in Europe or in the U.S.. None of the 
manufacturers interviewed were found to carry product guarantee insurance. Risk managers did not consider the product replacement costs for packaged goods to be a catastrophe as they can normally be borne by the company. They felt that such insurance seemed more suited for high cost products such as high technology equipment, rather than the low cost of packaged goods on which this study is based. The risk manager of a U.S. company summarised it all by saying that he looked upon product guarantee cover as being one of those gimmick or dummy policies which are aimed at risks not suitable for insurance, mainly risks which result in a large number of small losses.

\section{Legal outlook in Europe*}

There exist several types or degrees of legal liability in the world today.

- Fault liability - where the claimant has to prove that the manufacturer or some other person in the chain of production or distribution was negligent.

- Reversal of the burden of proof - where the manufacturer must prove himself innocent, rather than the claimant having to prove the manufacturer at fault.

- Strict liability - where the manufacturer is held liable independent of whether or not he is at fault.

Currently, the U.S.A. is the only country which has adopted a system of true strict liability. Manufacturers are held liable for any damage resulting from a product, regardless of whether a defect exists. In other words, negligence of the manufacturer is not a requirement for liability, and consumer error does not exempt manufacturers of indemnity.

The legal outlook in the U.S. has caused bitter complaint from manufacturers. They feel that they are being unjustly punished and that such legal liability laws encourage claims while restraining innovations.

As a result, there have been moves since about 1982 in the U.S. Congress, by both the Senate and the House or Representatives to introduce Federal legislation that will swing the pendulum slightly back towards the producer, i.e. in his favour. The chances of this effort succeeding are not very high, however, because of opposition from two sources: trial lawyers, whose presence in the U.S. Congress is significant, and consumers.

The U.S. product liability crisis is the result of peculiar features of the American system which do not exist in Europe. Some of these are:

- the judicial system which has created legal "inflation";

- the jury system which sets the awards, often too favourable to the victim;

- the concept of punitive damages;

- the contingency fee system which encourages more and larger claims to be made;

- liability without a limited period;

\footnotetext{
* Paper by John G. Cowell, Deputy Secretary General of the European Insurance Committee, Product Liability and Products Liability Loss Control, Paris, August 1982, and Product Liability The End of the Community Trail?, Paris, March, 1983.
} 
- "pure" strict liability, not allowing for consumer negligence to be used as a defence by the manufacturer;

- the social system which does not provide for an employee accident compensation scheme.

The European Commission submitted a proposal for a directive on liability for defective products to the Council of Ministers on the 26th of September 1979. Little progress has been made since then on finalising the text. There are four key issues believed to be under discussion in Brussels:

1) The principle of liability irrespective of fault.

2) Liability for the so-called development risk previously mentioned in section 2.4. of this report.

3) Inclusion of property damage.

4) Limitation of liability in amount.

It appears that the concept of strict liability as defined in the U.S.A. is somewhat changing as it comes to Europe. According to the draft directive, for the manufacturer to be held liable under liability irrespective of fault, the claimant is required to show damage, defect and causal link. This is not exactly strict and absolute liability as it exists in the U.S. even though evidence of fault is not required. Exemption from liability may be allowed in the case of injury or damage resulting from the act or omission of the claimant or a third party, and with proof of the non-existence of the defect at the time the product was marketed by the manufacturer. The draft directive also provides a limitation in time; three years from the date of discovery of the injury or damage and ten years from the date of having marketed the product.

In general, it can be said that liability in Europe is currently still based on fault. The various countries can be classified into two broad groups; those requiring fault, with the burden of proof of negligence being placed on the claimant, and those requiring only a presumption of fault, with the burden of proof of innocence being placed on the manufacturer.

The Table below shows the split of countries into the two categories:

$\begin{array}{cc}\text { Fault Liability } & \begin{array}{c}\text { Reversal of the Burden } \\ \text { of proof }\end{array} \\ \text { Denmark } & \text { Belgium } \\ \text { U.K. } & \text { France } \\ \text { The Irish Republic } & \text { Luxembourg } \\ \text { Federal Republic of Germany } & \\ \text { Italy } & \\ \text { The Netherlands } & \\ \text { Norway } & \\ \text { Sweden } & \end{array}$

The present situation in Belgium, France and Luxembourg is seen by many as being very similar to the system described in the proposed directive. Also, one finds that the trend is for the countries in the first category to move towards the more severe liability of the second category, i.e. the reversal of the burden of proof. 
In Germany, reversal of the burden of proof has been in effect for the pharmaceutical industry since 1968. The Thalidomide-Contegan disaster which hit Germany and elsewhere was a contributing factor in the development of the Pharmaceutical Law in Germany. This law, which was instituted in 1978, imposes liability irrespective of fault on the pharmaceutical industry and established an obligatory insurance cover of DM 200 million for all suppliers of drugs within Germany. The Pharmaceutical Law defines production and testing criteria for pharmaceuticals in addition to the legal terms of liability. The categories of pharmaceutical to which the law applies are defined as follows:

- Prescription drugs;

- Over-The-Counter (OTC) drugs bought only in pharmacies;

- OTC drugs bought anywhere.

Each category requires a different premium to be paid into the Pharmapool. The premiums are thus based for each company on the total sales turnover in each group of products. Around 150 German insurers provide cover for the Pharmapool, which contrasts with the Swedish approach (a true "pool" with the members bearing each other's risk, except for reinsurance). The Pharmaceutical Law imposes a liability limit of DM 200 million per drug, which is the loss incurred by GRUNENTHAL, the producer of Thalidomide-Contegan, and the German government as a result of that incident. German insurance companies, confronted with the necessity to make a DM 200 million coverage available, established the German Pharmapool. Under the pool arrangement, the underwriter provides the insured with a policy for DM 200 million for which they themselves are liable for only the first DM 10 million. The liability for any amount in excess of $\mathrm{Dm} 10$ million is passed on to the pool.

In Sweden, there has been a growing trend towards a more severe interpretation of the notion of fault. The Thalidomide case had consequences similar in Sweden to those in Germany. A proposal was submitted by a governmental body to establish strict liability in the Swedish pharmaceutical industry. In order to avoid this legislation, the pharmaceutical industry entered into a voluntary agreement with a group of four major Swedish insurers to form a combined insurance cover which would offer the same protection to the consumer as strict liability law. Thus the Swedish Pharmapool was established in 1976 and strict liability legislation was not introduced. There had also been talk of introducing strict liability in general to all sectors of industry, but once the Pharmapool was formed, these ideas died down. It can therefore be said that the Pharmapool scheme was developed to, and successfully did, avoid strict liability legislation in Sweden while allowing a system of strict liability to evolve voluntary for pharmaceutical industry. The indemnity limits of the Pharmapool are as follows:

- SKr 2 million per person.

- SKr 15 million per drug.

- SKr 150 million per year.

Over the years, a system for compensation from the Pharmapool for claimants has been developed to include:

- Economic compensation based on status.

- Pain and suffering compensation which is made according to a highly regulated listing of the values of different injuries developed from general damage experience in Sweden. 
There are distinct differences berween the German and Swedish Pharmapools. In Germany, the pool was established by insurance companies concerned, while in Sweden it was an arrangement made between the pharmaceutical industry and a group of major insurers. Furthermore, in Germany the pool covers only amounts in excess of DM 10 million, the underwriters being liable for the first DM 10 million. In Sweden, on the other hand, only a very limited deductible is applied which is not covered by the pool.

Liability irrespective of fault (the expression is more correct in Europe than "strict liability"), therefore, is not an entirely new concept in Europe. In addition to being applied in the German and Swedish pharmaceutical industries, it exists in Belgium, France and Luxembourg under case law, i.e. legal precedence. In the U.K. liability irrespective of fault is used to protect individuals who directly purchase goods from suppliers (Sales of Goods Act) and the patients involved in clinical tests for pharmaceutical companies. This movement towards stricter liability in Europe can be partly attributed to growing product sophistication resulting in increased risk of defect in design, manufacture and labelling of products, as well as to a growing consumer awarness of product accident risks and the need for improved product safety.

It is believed that the European Council of Ministers is increasingly leaning in favour of accepting the principle of liability irrespective of fault, although there are questions regarding the scope of application, particularly regarding the so-called development risk. The 1979 text submitted by the European Commission retained liability for the development risk, against the advice of the European Parliament. The proposed directive is intended to impose liability for latent defects (defects only discoverable by dismantling the products or only becoming apparent several years after the products' manufacture), while excluding liability for subsequent defects (defects only becoming apparent due to improved scientific or technological knowledge after the product has been marketed). As was previously mentioned in this report, latent defects are referred to as "development risk", whereas subsequent defects are represented by the expression "state-of-the-art". However, the opposition that has arisen regarding these concepts suggests that some changes to the text are to be expected.

The 1979 draft of the directive covers personal and private property damage in addition to death and bodily injury, and proposes the following limitations or financial ceilings on the amount of liability:

- 25 million ECU (about $£ 16.5$ million) for bodily injury "caused by identical articles having the same defect" (article 7.1).

- 50,000 ECU (about $£ 33,500$ ) per capita for immovable property and 15,000 ECU (about $£ 10,000)$ per capita for movable property (article 7.3 ).

The idea of limitation on liability was inspired by Germany and Sweden, who set such limitations in the process of forming their respective Pharmapools. Questions arise, however, as to whether such a legal limitation to liability can be of any real practical use when it is applied to all products. For pharmaceuticals, for example, the limit might prove too low, providing inadequate protection to the consumer. But a limit which is inappropriately high for certain products could become the target for all claims. Nevertheless, at least one risk manager interviewed has used the EEC proposed limitation on liability as a basis for choosing the limit of his company's product liability policy. 
It is a possibility, however, that the concept of liability limitation will not be accepted by the Council. This should not pose a problem to European insurers. On the contrary, their task would be made considerably easier. The absence of any legal limitation would be to the advantage of the underwriter who can then be free to negotiate the level of insurance coverage necessary with his client based on factors such as:

- type of product;

- loss exposure;

- current levels of court awards;

- number and cost of previous claims;

- availability and cost of insurance cover;

- catastrophe potential.

At present, legal liability is unlimited even in those countries closest to the system of the draft directive, with two exceptions:

1) The Federal Republic of Germany where a limit of DM 200 million per product is imposed on liability regarding pharmaceuticals.

2) Sweden where a similar scheme to that in Germany exists for pharmaceuticals, with a limit on liability of SKr 2 million per person, SKr 15 million per drug and $\mathrm{SKr} 150$ million per year.

The latest position of the Council of Ministers on the proposal for a directive is as follows:

- exclusion of the development risk;

- exclusion of material damage;

- maintaining a financial limitation.

This position is by no means final, however, as the following criticisms of this stand by individual countries have been levelled:

- such a directive achieves nothing since it gives protection to the consumer by adopting liability irrespective of fault and then reduces that protection by imposing a financial limit on liability;

- countries which practice a reversal of the burden of proof currently provide superior consumer protection to that of such a directive.

Should liability irrespective of the fault of the manufacturer be introduced in the European Community, insurers would expect an increase in the number of claims made as well as claims paid. It is not certain, however, that such an increase would occur. For example, when strict liability was enforced in the pharmaceutical industry in Germany and the compulsory insurance (Pharmapool) was established, insurers initially set the premiums too high wing to their expectations of an increase in the number of claims paid. The number of claims, however, did not increase, and to this day there has been no need by pharmaceutical companies to draw upon the Pharmapool. As a result, the insurers have had to decrease the premium requirements since the establishment of the Pharmapool in 1978 by $15 \%$ in January 1981, and again in January 1985 by $9 \%$. 
Whether the directive is seen as a coordination or harmonisation effort will have certain consequences on insurers. A minimum directive, which would allow derogations by individual countries over and above the protection provided for under the directive will create greater confusion, which will cost money to insurers. A maximum directive, which would disallow any derogations by individual countries, will increase harmonisation which is in the interest of insurers. Harmonisation of the laws should speed-up the settlement of claims thereby reducing the reserve requirements, and consequently the costs, of insurers. The introduction of liability irrespective of fault in Europe would have the similar effect of reducing claim settlement time to the benefit of the insurers.

\section{Conclusions}

The insurance industry has responded well to the changing needs of the packaged goods industry. However, the responses up to this day have been triggered by the major disaster incidents such as the Thalidomide and Tylenol cases. The Thalidomide incident helped create the Pharmapools in Germany and Sweden, and increased the availability of product liability insurance - then not widespread in Europe -, particularly in these two countries. The Tylenol case led to the development of the product integrity cover by U.S. insurers, and increased awareness for the need of product recall coverage in the U.S.. One might ask is whether a similar Tylenol incident must occur in Europe before similar developments there create interest in covers such as extortion, product recall and product integrity.

\subsection{Liability irrespective of fault}

Europe is headed in the direction of more severe liability laws, and the introduction of legislation for the European equivalent of strict liability (liability irrespective of fault) is expected. This movement towards consumer protectionism, is not, however, necessarily an indication that Europe will follow the U.S. route to (virtually) unconditional liability of the manufacturer.

The expected changes in legislation are likely to have a favourable impact on insurers: the enforcement of stricter liability laws will reduce the gap between the objectives of the manufacturer of maintaining a good image with consumers by settling claims and those of the insurer of minimising claim settlements:

- stricter liability laws, particularly if instituted by a European Community directive, will translate into financial benefits to insurers since it will reduce confusion and claim settlement time, and hence the insurers' requirement for reserves.

\subsection{Product recall and integrity}

In the U.S.A., some concepts of insurance have developed which are not yet significant in Europe, notably product recall and product integrity. The increase in the U.S.A. of criminal activity in general, and, more specifically, of malicious tampering and extortion, has created the need for, and hence is the main cause of, these new developments. In Europe, such criminal activity is not quite so widespread as in the U.S.A.. Furthermore, the different philosophy in Europe from that of the U.S.A. has prevented the development of these new concepts. In 
the U.S.A., any catastrophe-type incident is considered suitable for the insurance market, whereas many such events are considered in Europe as business risks which should be borne by the manufacturer out of ethical considerations.

New concepts in insurance such as product integrity are aimed at reducing a company's vulnerability. However, due to the fact that insurers have difficulty in quantifying the costs of newly developed covers, high premiums to account for the "unknown" factor are charged. This results in these policies only being affordable by industry giants, but these are normally diversified and are not so vulnerable to a catastrophic incident as are smaller companies with a limited product line. Product integrity cover, therefore, is not made available and does not serve those (medium-sized) packaged goods companies which require it the most.

Market presence of brand names or the loss thereof is a major preoccupation for packaged goods manufacturers. The long term loss of sales resulting from a product's market absence for a finite time are often much more significant than the direct costs associated with a business interruption. The traditional consequential loss insurance, which in Europe can, in certain instances, pick up sales loss of a business interruption due to fire or machinery breakdown, is generally insufficient coverage for packaged goods. Product integrity insurance is a type of consequential loss cover tailored to the packaged goods industry which attempts to pick up the long term profit loss caused by a product's limited absence from the market due to a defect necessitating recall.

\subsection{Flexibility in claims-response}

The general attitude within the packaged goods industry seems to be one of preference for manoeuvreability to make commercial settlements. This attitude was expressed by a majority of the packaged goods manufacturers and the packaging/packaging systems manufacturers, although for very different reasons. Packaged goods manufacturers can be described as being multi-national, highly visible companies whose products are household names. Their interest, therefore, is to have a good image with the public, and hence they need to have flexibility of settling claims regardless of legal liability.

The packaging/packaging systems manufacturers, on the other hand, are classified as being engineering companies with industrial customers, unknown to the public, and operating on the basis of long client relationships. In order to establish their reliability with their clients, they favour a friendly settlement on a commercial basis rather than getting involved with an insurer as an intermediary. To them, litigation with a client can only lead to a decline of business.

\subsection{Insurer/Insured relations}

The continued development of the insurance industry in Europe, particularly in the area of nonclassical risks, requires that underwriters have a good relationship with their clients. The proper functioning of new types of policy, such as product integrity, demands the mutual trust of both parties. In order to avoid controversies such as that currently underway between JOHNSON \& JOHNSON and their underwriters, the insurer and his client must work closely together to form a contract which they both interpret the same way. Evidence suggests, for example, that, with regards to the product integrity cover, interpretations of wording, methods of establishing the profit loss incurred, and data required for such determination 
must be agreed upon prior to the signing of the contract. The insurer must determine his client's needs and expectations regarding the cover.

The intense competition within the insurance industry has had a negative effect on the relationship between underwriters and manufacturers. The general trend observed is that manufacturers are losing their loyalty towards their insurers. They tend to search more for lower rates and broader service, and consequently cause the broker's role to increase in importance. Frequent shifting of insureds from one insurer to another can represent an obstacle to the development of the insurance industry for which the basis is mutual trust gained in longterm relationships between insurers and insureds. One way that insurers can improve the situation is by putting an emphasis on having frequent, periodical negotiations with their clients on rates and terms of policies.

\author{
Appendix: \\ Evolution of the packaging industry
}

\title{
Background
}

Packages, or at least containers, have been in use for centuries, with blown glass having been first developed in the seventeenth century. Modern day packaging, however, can be traced to 1795 when Napoleon offered a FFr. 12,000 prize for a method of preserving food. This was won 15 years later by a Frenchman using sterilisation, and at about the same time tinplated iron cans were patented.

In the early 20 th century, the major packaging materials were still glass and tin-plate. Developments to these products include the roll-on closure and the pry-off cap for glass bottles (both in the 1920's) and flat top beer cans in the 1950's. Also during this period the aluminium tube, which was first used for toothpaste in the 1890's, became increasingly important.

Most of the major developments came after the 1950's and resulted from the use of plastics as packaging materials and from a rapid parallel growth in demand for packages. Until this time packaging was seen as a necessary evil, a costly means of meeting safety and quality requirements.

The first plastic material - Celluloid - was discovered in the 1860 's but it was not until the period 1920 to 1940 that most of today's products were found (cellophane, PVC, polythene). Nevertheless, by 1960 the amount of plastics used in packaging was still very small.

Initial inroads were made in toiletries and cosmetics, with pharmaceuticals and, particularly, food and beverages moving much more slowly to the use of, for example, plastic bottles.

However, the main thrust to packaging changes of the last twenty years has been the change in lifestyles. Car ownership has increased, as have leisure time and the number of working women. At the same time supermarkets have grown in importance. While their initial justification was solely to sell convenience foods, they are now a major force in retailing. 
Their success has also prompted a big move to self service in all stores. The result of the decline of the corner shop has been a trend to packaged goods rather than goods which have simply been wrapped at the point of purchase.

\section{Pacakge types}

The following exhibit - based on recent UK data, but broadly representative of Europe as a whole - indicates the importance of the different types of package.

Major UK packaging products

\begin{tabular}{|c|c|c|c|c|}
\hline \multirow[b]{2}{*}{ Open Top Cans } & \multicolumn{2}{|c|}{$\begin{array}{l}\text { UK demand } \\
\text { (million pieces) }\end{array}$} & \multirow{2}{*}{$\begin{array}{l}\text { Trend } \\
\text { Down }\end{array}$} & Main applications \\
\hline & 9,500 & $43 \%$ & & $\begin{array}{l}\text { Pet foods, fruit and vegetables, } \\
\text { pasta, soups. }\end{array}$ \\
\hline Glass Containers & 6,300 & $29 \%$ & Down & $\begin{array}{l}\text { Food, liquor, soft drinks, } \\
\text { pharmaceuticals, milk, beer. }\end{array}$ \\
\hline $\begin{array}{l}\text { Thin Wall Plastic } \\
\text { Containers }\end{array}$ & 2,300 & $10 \%$ & Up & $\begin{array}{l}\text { Margarine, yoghurt, desserts, } \\
\text { cream. }\end{array}$ \\
\hline Blown Plastic Bottles & 2,100 & $10 \%$ & Up & $\begin{array}{l}\text { Cosmetics, detergents, juices, } \\
\text { bleaches, hair care. }\end{array}$ \\
\hline Aluminium Tubes & 600 & $3 \%$ & Static & Toothpaste, pharmaceuticals. \\
\hline Aerosols & 500 & $2 \%$ & Static & $\begin{array}{l}\text { Hair care, personal care, insecti- } \\
\text { cides, cleaners, pharmaceuticals }\end{array}$ \\
\hline Laminated Cartons & 400 & $2 \%$ & Up & Fruit juices, milk. \\
\hline Plastic Tubes & 100 & $1 \%$ & Static & Handcreams, pharmaceuticals. \\
\hline & 21,800 & $100 \%$ & & \\
\hline
\end{tabular}

Open top cans are the single largest packaging method, used predominantly for food applications, but they are declining in use with the trend to fresh foods.

Glass containers are similarly declining as both cans and plastic bottles make in-roads on their usage.

Thin wall plastic containers are growing rapidly and used mainly in dairy products.

Blown plastic bottles are similarly growing and moving from their initial strongholds, as cosmetics and detergents move into food markets.

These are the four largest packing product groups representing $90 \%$ of units. 
Aluminium tubes have made little progress out of the generally static toothpaste market, while plastic tubes have only had partial success and have been limited to handcreams and pharmaceuticals.

Similarly aerosols have been a static market in the 1980's partly due to the anti-fluorocarbon propellant lobby, with increasing competition from roll-on's and spray pumps.

Finally, laminated cartons (of the aseptic packaging type invented by TETRAPAK) are a rapidly growing market in the areas of fruit juices and milk.

\section{Future Trends}

There are a number of trends in the types of packaging used that could have implications for product recall:

- crown corks are declining as returnable bottle demand falls while conversely, roll-on caps are becoming increasingly important;

- some food manufacturers (notably in France) are making plastic bottles in-house - particularly for water, edible oils, detergents and dairy products;

- some pressure from the EEC (but receiving resistance from the industry, especially the UK) for potable liquids to be in returnable/recyclable containers;

- possible legislation on tamper-proof packages (stimulated by the Tylenol incident);

- trend to larger pack sizes;

- trend to long life packages such as retortable pouches (foil/plastic laminate) and aseptic cartons.

Table I: Main classes of risk to which packaged goods are exposed

\begin{tabular}{|c|c|c|c|}
\hline $\begin{array}{c}\text { Formula } \\
\text { errors }\end{array}$ & $\begin{array}{l}\text { Manufacturing } \\
\text { faults }\end{array}$ & Tampering & $\begin{array}{c}\text { Faulty } \\
\text { packaging }\end{array}$ \\
\hline
\end{tabular}

\begin{tabular}{|c|c|c|c|c|}
\hline Pharmaceuticals & $\mathrm{xx}$ & & $\mathrm{xx}$ & $\mathrm{x}$ \\
\hline Food and drink & $\mathrm{x}$ & $\mathrm{x}$ & $\mathrm{xx}$ & $\mathrm{x}$ \\
\hline $\begin{array}{l}\text { Cosmetics and } \\
\text { toiletries }\end{array}$ & $\mathrm{x}$ & $\mathrm{X}$ & $\mathrm{xX}$ & $\mathrm{X}$ \\
\hline
\end{tabular}

Household goods

$\mathrm{X}$

$\mathrm{X}$

$\mathrm{xX}=\mathrm{a}$ particular risk to this sector

$\mathrm{X}=$ can also apply here 


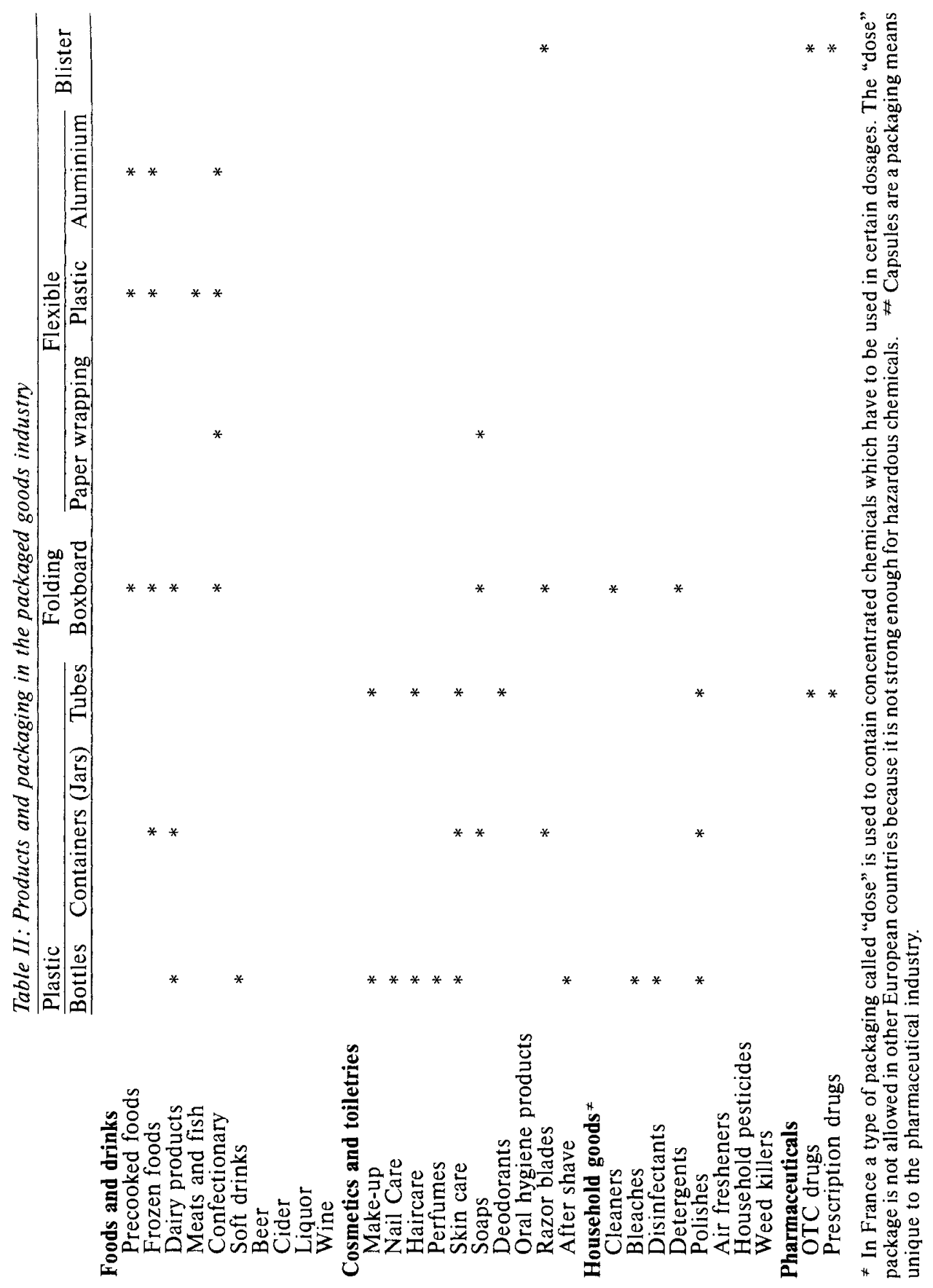


Table III: Breakdown of types of insurance cover used by manufacturer interviewed (Percentages)

\begin{tabular}{lrrrrr} 
& U.S. & U.K. & France & Germany & Sweden \\
\cline { 2 - 6 } $\begin{array}{l}\text { Product liability } \\
\text { Consequential loss } \\
\text { Product recall }\end{array}$ & 100 & 100 & 100 & 100 & 100 \\
\cline { 2 - 6 } & 100 & 44 & 75 & $25^{\text {b }}$ & 100 \\
Extortion & 20 & 11 & 50 & 0 & 0 \\
Product integrity & N/A $^{3}$ & 22 & 0 & 0 & $0^{\text {a }}$ \\
Product guarantee & 20 & 0 & 0 & 0 & 0 \\
\hline
\end{tabular}

1. It is not permitted to insure against extortion in France and Germany.

2. In Germany and Sweden product recall covers apply mainly to the automobile industry.

3. U.S. companies were particularly sensitive about revealing whether or not they have extortion cover.

a. One company was seeking extortion insurance.

b. The company which had consequential loss coverage used it only for its industrial products and not its consumer (packaged goods) products, the reason being that the loss due to a consumer product being off the market for a long period of time is greater from the marketing (consumer awareness) impact than the manufacturing.

Table IV: Percent of manufacturers interviewed which have a captive insurance company

\begin{tabular}{cccccc} 
& U.S. & U.K. & France & Germany & Sweden \\
\cline { 2 - 6 } Captive insurance company & 100 & 56 & 75 & $33^{\mathrm{a}}$ & 33 \\
\cline { 2 - 6 }
\end{tabular}

a. In Germany, a captive insurance company cannot exist as in other European companies. It must be licensed by the Federal Supervisory Office for Insurance and registered as an insurance company.

Table V: Percent of manufacturers which have a product recall plan and practice contingency planning

U.S. U.K. France Germany Sweden

\begin{tabular}{llllll} 
Product recall plan & 67 & 27 & 0 & 33 & 33 \\
\cline { 2 - 6 } Contingency planning & 33 & 18 & 20 & 67 & $67^{\mathrm{a}}$ \\
\hline
\end{tabular}

a. This percentage includes companies which are starting to do some work in contingency planning. 


\begin{tabular}{|c|c|c|c|c|c|}
\hline & $\begin{array}{l}\text { U.S. } \\
\text { (\$MM) }\end{array}$ & $\begin{array}{l}\text { U.K. } \\
\text { (fMM) }\end{array}$ & $\begin{array}{l}\text { France } \\
\text { (FFMM) }\end{array}$ & $\begin{array}{l}\text { Germany } \\
\text { (DMMM) }\end{array}$ & $\begin{array}{l}\text { Sweden } \\
\text { (SkrMM) }\end{array}$ \\
\hline \multicolumn{6}{|l|}{ Product liability } \\
\hline $\begin{array}{l}\text { deductible } \\
\text { primary layer } \\
\text { excess layer }\end{array}$ & $\begin{array}{c}0-7.5^{*} \\
.25-1 \\
20-200^{\neq}\end{array}$ & $\begin{array}{c}0-0.5 \\
1-2 \\
15-50\end{array}$ & $\begin{array}{c}.001 \\
10-20 \\
200-300\end{array}$ & $\begin{array}{c}0-.02 \\
20 \\
100-300\end{array}$ & $\begin{array}{c}.0005-.5 \\
10 \\
250-300\end{array}$ \\
\hline \multicolumn{6}{|l|}{ Consequential loss } \\
\hline $\begin{array}{l}\text { deductible } \\
\text { local policy } \\
\text { DIC }\end{array}$ & $\begin{array}{r}0 \\
24 \\
100\end{array}$ & $\begin{array}{c}0 \\
\text { N/A } \\
220\end{array}$ & $\begin{array}{c}25 \\
250-375 \\
\text { N/A }\end{array}$ & N/A & N/A \\
\hline $\begin{array}{l}\text { Product recall } \\
\text { deductible } \\
\text { limit }\end{array}$ & $* *$ & $\begin{array}{r}.025 \\
\text { N/A }\end{array}$ & N/A & - & - \\
\hline $\begin{array}{l}\text { Extortion } \\
\text { deductible } \\
\text { limit }\end{array}$ & N/A & $\begin{array}{c}.005 \\
2\end{array}$ & - & - & - \\
\hline $\begin{array}{l}\text { Product integrity } \\
\text { deductible } \\
\text { limit }\end{array}$ & $\begin{array}{c}10 \\
100^{\neq}\end{array}$ & - & - & - & - \\
\hline Product guarantee & - & - & - & - & - \\
\hline
\end{tabular}

* Pharmaceutical companies tend to have large deductibles, which explains the $\$ 7.5$ million figure.

** Included as part of the integrity cover.

* \$100 million was the maximum limit or capacity of the market for product integrity when the cover was first introduced. Since then, however, the market has been shrinking and the capacity seems to have declined to $\$ 25$ million according to one of the few U.S. insurers who supplies this cover, although a limit of $\$ 100$ million can be obtained with facultative reinsurance.

\#Industry giants in the U.S. normally have product liability covers of over $\$ 100$ million. An average limit for a sizeable company would be around $\$ 50$ million. 